\title{
SOBRE LA EQUIVALENCIA PRAGMÁTICA ENTRE PERMISO Y NO PROHIBICIÓN *
}

\author{
Eugenio Bulygin ${ }^{1}$ \\ Universidad de Buenos Aires
}

RESUMEN. En este artículo, E. BuLYGin aborda, una vez más, el problema del status lógico de los permisos y de las normas permisivas. BULYGIN defiende la pertinencia de la triple clasificación de los permisos que ofreciera, junto con C. Alchourrón, en Normative Systems. De acuerdo con esta obra, debe distinguirse entre un concepto prescriptivo y dos conceptos descriptivos de permisión (fuerte y débil). La pertinencia y el alcance explicativo de estas distinciones han sido puestos en cuestión en algunos trabajos recientes, y estas «nuevas herejías» - dice E. BULYGIN- «me obligan a empuñar nuevamente la pluma en defensa de la ortodoxia». Esta defensa desemboca en un conjunto de conclusiones, de las que parecen de especial importancia las siguientes: no existe la pretendida equivalencia pragmática sostenida por algunos críticos entre la no prohibición y la permisión; las normas permisivas son normativamente relevantes, pues cumplen múltiples funciones normativas; la concepción del Derecho que comprende reglas y principios subyacentes es irrelevante para el problema de la equivalencia entre regulación negativa (no prohibición) y permisión y para la caracterización de las lagunas normativas; las decisiones judiciales que hacen lugar a la demanda y las que la rechazan son simétricas.

Palabras clave: permisos, normas permisivas, permiso prescriptivo, permiso débil, permiso fuerte, lagunas normativas, discreción judicial.

ABSTRACT. In this article, E. BULYGIN once again approaches the problem of the logical status of permissions and permissive norms. BULYGIN supports the appropriateness of the triple classification of permissions which he, together with C. ALCHOURRÓN, presented in Normative Systems. In accordance with this work, a distinction must be drawn between a prescriptive concept and two descriptive concepts of permission (strong and weak). The appropriateness and the explanatory reach of these distinctions have been questioned in some recent works and, in the words of E. BULYGIN, these «new heresies have made me take up my pen again in defence of orthodoxy». This defence results in a number of conclusions of which the most important appear to be the following: the so called pragmatic equivalence believed by some critics to be found between nonprohibition and permission does not exist; permissive norms are normatively relevant, since they perform numerous normative functions; the conception of law which includes rules and underlying principles is irrelevant both with regard to the problem of equivalence between negative regulation (non-prohibition) and permission, and with regard to the characterization of normative gaps; judicial decisions which admit a claim and those which dismiss it are symmetrical.

Keywords: permissions, permissive norms, prescriptive permission, weak permision, strong permission, normative gaps, judicial discretion.

* Fecha de recepción: 5 de marzo de 2011. Fecha de aceptación: 5 de abril de 2011.

${ }^{1}$ Quisiera expresar mi profundo agradecimiento a Cristina Redondo, Jorge Rodríguez y Lars Lindahl por sus críticas y sugerencias que permitieron corregir algunos de (aunque debido a mi obstinación no todos) los errores o formulaciones confusas. 
«It has taken me nearly thirty years to see its full significance. And not all logicians and philosophers have seen it even now."

G. HENRIK VON WRIGHT ${ }^{2}$

(Refiriéndose a la distinción entre normas y proposiciones normativas).

1.

$\mathrm{E}$

1 status lógico de los permisos y de las normas permisivas ha sido objeto de muchas dudas y controversias entre los lógicos deónticos y filósofos interesados en normas y conceptos normativos. Muchos autores importantes han sostenido que la permisión no es más que la ausencia de prohibición e incluso han negado la existencia o la relevancia de normas permisivas. Este tema está relacionado con varios problemas claves para la teoría del Derecho, tales como la posibilidad de las lagunas en el Derecho, la completitud del Derecho, el status del famoso principio «Todo lo que no está prohibido, esta permitido», las normas de clausura, la función del juez, la discreción judicial y varios otros.

En Normative Systems (en adelante NS) ${ }^{3}$ distinguimos con C. ALCHOURRÓN tres conceptos de permiso: un concepto prescriptivo que figura en las normas permisivas y dos conceptos descriptivos que aparecen en las proposiciones normativas, es decir, proposiciones descriptivas (verdaderas o falsas) que versan sobre las normas. La falta de distinción entre normas y proposiciones normativas es la raíz de las dificultades y problemas relacionados con el tema de las normas permisivas y los permisos.

El concepto prescriptivo de permiso se usa para permitir una cierta conducta en determinadas circunstancias. Es un concepto no relativo, sino absoluto, en el sentido que CARNAP da a este término ${ }^{4}$, es decir, no se refiere a una relación, sino a una propiedad. Las normas que permiten o autorizan conductas son llamadas «normas permisivas».

Los dos conceptos descriptivos de permiso son relativos en el sentido de que establecen una relación entre una acción o un estado de cosas $(p)$ y un conjunto de normas o sistema normativo $(\alpha)$. Cabe distinguir aquí entre un permiso negativo o débil y un permiso positivo o fuerte; las respectivas definiciones son las siguientes:

Definición de permiso negativo: $p$ está permitido en el sentido negativo o débil en $\alpha==_{\text {df. }} \alpha$ no contiene ninguna norma que prohíba $p$.

Definición de permiso positivo: $p$ está permitido en el sentido positivo o fuerte en $\alpha={ }_{\mathrm{df}} \cdot \alpha$ contiene una norma que permite $p$.

Dicho de otro modo: la expresión «prohibido $p »(« 0 \sim p »)^{5}$ admite dos tipos de negación, externa e interna. La negación externa de «prohibido $p »(« 0 \sim p » \notin \alpha)$ significa

${ }^{2}$ G. H. von Wright, «Value, Norms, and Action in my Philosophical Writings», en G. Meggle (ed.), Actions, Norms, and Values. Discussions with Georg Henrik von Wright, Berlin-New York, de Gruyter, 1999, 11-33.

3 C. E. Alchourrón y E. Bulygin, Normative Systems, Wien-New York, Springer Verlag, 1971. Versión castellana Introducción a la metodología de las ciencias jurídicas y sociales, Buenos Aires, Astrea, 1975.

${ }^{4}$ R. CARNAP, Introduction to Semantics.

${ }^{5}$ Uso los siguientes símbolos para los operadores deónticos: P (permisión), 0 (obligación) y 0 (prohibición). 
que la norma «prohibido $p »$ no pertenece a $\alpha$ (= permisión negativa o débil), mientras que la negación interna de «prohibido $p »(« \sim 0 \sim p » \in \alpha)$ significa que la norma «no prohibido $p$ » pertenece a $\alpha$ (= permisión positiva o fuerte).

Estas distinciones nos permitieron mostrar la ambigüedad del principio «Lo que no está prohibido está jurídicamente permitido» (en adelante principio de probibición), que algunos autores y en especial KELSEN usan para sostener que todo Derecho es necesariamente completo y, por tanto, no puede haber lagunas en el Derecho.

Si el principio es una norma positiva, entonces su existencia (como la de toda norma) es contingente y no puede pertenecer necesariamente a todos los sistemas normativos. Y si es una proposición normativa entonces o bien «permitido» es negativo, en cuyo caso el principio dice que lo que no está prohibido no está prohibido, lo cual es analíticamente verdadero, pero trivial, o bien se trata de un permiso positivo, en cuyo caso el principio es contingente, pues de la ausencia de una norma prohibitiva no cabe inferir la existencia de una norma permisiva ${ }^{6}$.

Con este análisis creímos haber resuelto el problema en forma definitiva, pero esto resultó ser una ilusión. Como ya lo sabía Tomás de Torquemada, el exterminio de las herejías no es tarea fácil.

En consecuencia, algunos años después publicamos con C. AlCHOURRÓN un artículo $^{7}$ crítico de las diversas objeciones a la idea de las normas permisivas y de la distinción entre permisos positivos (fuertes) y negativos (débiles), en el que analizamos varios trabajos y en especial las criticas de OPALEK y WOLENSKI ${ }^{8}$, RAZ $^{9}$, A. ROSS ${ }^{10}$ y ECHAVE, URQUIJO y GUIBOURG ${ }^{11}$.

Lamentablemente, nuestras respuestas a esas críticas no lograron acallar todas las voces disidentes. Últimamente han surgido nuevas herejías que me obligan a empuñar nuevamente la pluma en defensa de la ortodoxia. En los últimos tiempos varios amigos me han reprochado no haber cambiado mis ideas en los casi cuarenta años que transcurrieron desde la publicación de NS, lo cual es cierto... respecto de este tema. Siento mucho parecer testarudo y anquilosado (lo cual no sería tan extraño, dada mi edad), pero sigo pensando que la verdad es atemporal y que el viejo adagio «amicus Plato, sed magis amica veritas» conserva su validez.

${ }^{6}$ Esto es lo que BAYÓN llama el trilema de BuLYGIN.

7 C. E. Alchourrón y E. Bulygin, «Permissions and Permissive Norms», en W. Krawietz et al. (eds.), Theorie der Normen, Berlin, Duncker Humblot, 1984; traducción castellana «Permisos y normas permisivas» en Alchourrón y Bulygin, Análisis lógico y Derecho, Madrid, Centro de Estudios Constitucionales, 1991, 215-238.

${ }^{8}$ K. OpaleK y J. WOLENSKI, «On weak and strong permissions», Rechtstheorie, núm. 4 (1973), 169-182.

9 J. Raz, Practical Reason and Norms, London, Hutchinson, 1975.

10 A. Ross, Directives and Norms, London, Routledge and Kegan Paul, 1968.

${ }^{11}$ D. T. Echave, M. E. Urquijo y R. A. Guibourg, Lógica, proposición y norma, Buenos Aires, Astrea, 1980, en adelante EUG. 
2.

La nueva herejía se origina en el conocido libro de M. AtIEnZA y J. RUIZ MANERO Las piezas del Derecho ${ }^{12}$, se propaga en un excelente ${ }^{13}$ artículo de RUIZ MANERO ${ }^{14}$ y alcanza su apogeo en un trabajo de J. C. BAYÓN ${ }^{15}$.

En Las piezas del Derecho figura todo un capítulo dedicado a los enunciados permisivos y los permisos. Allí los autores analizan en primer lugar una serie de concepciones de permisos en la teoría jurídica contemporánea: ECHAVE-URQUIJO-GUIBOURG (1980), A. Ross (1971), VON WRIGHT (1963) y ALCHOURRÓN-BULYGIN (1971), para luego proponer su propia teoría.

Cabe destacar tres tesis en la teoría de ATIENZA y RUIZ MANERO (en adelante ARM), que me parecen harto dudosas y que por tanto merecen especial comentario.

1) La tesis de la equivalencia pragmática entre la regulación permisiva y la ausencia de regulación y la consiguiente tesis de la irrelevancia de las normas permisivas.

2) La tesis del carácter no independiente de permitido respecto de la prohibición y del carácter superfluo de las normas permisivas.

3) La tesis de la equivalencia de no prohibición y la regulación jurídica, consistente en que todas las conductas no prohibidas son consideradas como reguladas por el Derecho.

\section{Ad 1) Dicen ARM:}

«Es un lugar común entender que la función más primaria de cualquier sistema normativo es la de guiar la conducta humana. En el caso de las normas de mandato, esta función de guía de la conducta se lleva a cabo estipulando, bien la obligación de realizar una determinada acción $p$ en un determinado caso $q$ (o, lo que es lo mismo, la prohibición de omitir realizar $p$ en $q$ ), bien la prohibición de realizar $p$ en $q$ (o, lo que es lo mismo, la obligación de omitir $p$ en q). Esto es, las normas de mandato, que pueden expresarse bajo la forma de obligaciones o de prohibiciones, ordenan, bien realizar una determinada acción, bien omitirla y, así deslindan la esfera de lo lícito de la de lo ilícito. Por el contrario, las normas permisivas —entendiendo por tales las que permiten en un determinado caso $q$, tanto la realización como la omisión de una determinada acción $p$ - no ordenan nada. Pues bien, cuando nos encontramos frente a una norma de este tipo, frente a una norma que permite la realización y también la omisión de $p$ en el caso $q$, ¿la situación es pragmáticamente equivalente a la que se daría en el supuesto de que no hubiera ni una norma que prohibiera ni una norma que obligara a realizar $p$ en $q$ ? ¿Introduce la supuesta norma permisiva algo que no se dé en la mera ausencia de norma o más bien aquélla es pragmáticamente irrelevante?» (91-92).

Estas preguntas son manifiestamente retóricas, pues los autores no dudan de que merecen una respuesta afirmativa.

\footnotetext{
${ }^{12}$ M. AtienZa y J. Ruiz Manero, Las piezas del Derecho, Barcelona, Ariel, 1996.

${ }^{13}$ Como se sabe, la excelencia de un trabajo filosófico no excluye en absoluto que contenga errores.

14 J. Ruiz MANERO, «Algunas concepciones del Derecho y sus lagunas», en F. AtriA et al., Lagunas en el Derecho, Madrid-Barcelona, Marcial Pons, 2005, 105-126.

15 J. C. BAYÓN, «Sobre el principio de prohibición y las condiciones de verdad de las proposiciones normativas», en E. Bulygin, M. AtIENZA y J. C. BAYÓN, Problemas lógicos en la teoría y práctica del Derecho, Madrid, Fundación Coloquio Jurídico Europeo, 2009, 27-73.
} 
Nosotros ya tuvimos la ocasión de señalar —al contestar la crítica de EUG- que la impresión de que da lo mismo que una conducta esté permitida por una norma (sentido positivo de permiso) o simplemente no prohibida (sentido negativo de «permitido») proviene de considerar las normas aisladas. Cuando se trata en cambio de un conjunto de normas estructuradas jerárquicamente —como ocurre habitualmente en el campo del Derecho- el dictado de una norma permisiva por una autoridad superior suele limitar la competencia de las autoridades inferiores y en este sentido cumple importantes funciones normativas. Pero éste no es el único caso en que las normas permisivas resultan relevantes.

El siguiente experimento mental demuestra claramente que las normas permisivas son normativamente relevantes y de ninguna manera pueden ser consideradas superfluas. Tomemos dos conjuntos de normas $\alpha$ y $\beta$; ambos conjuntos son consistentes y sólo difieren entre si en que $\alpha$ no contiene ninguna norma referente a la acción $p$, mientras que $\beta$ contiene una norma permisiva «Permitido $p »$. De acuerdo a la tesis de la equivalencia pragmática, los dos conjuntos son normativamente equivalentes, pues tienen las mismas consecuencias normativas. Ahora bien, si agregamos una misma norma a cada uno de esos conjuntos, los conjuntos resultantes: $\alpha$ ' y $\beta$ ' tendrían que ser normativamente equivalentes. Sin embargo, si la norma que agregamos es «Prohibido $p$ », $\alpha^{\prime}$ y $\beta^{\prime}$ ya no son equivalentes. El agregado de «Prohibido $p$ » al conjunto $\alpha$ no genera inconsistencia alguna: la única diferencia es que $p$ no estaba prohibida en $\alpha$ y ahora está prohibida en $\alpha$ ', pero tanto $\alpha$, como $\alpha$ ' siguen siendo consistentes. En cambio, el agregado de la misma norma «Prohibido $p$ » al conjunto $\beta$ produce una inconsistencia en el conjunto $\beta$ ' pues las normas «Permitido $p$ » «Prohibido $p$ » con incompatibles. Esto demuestra, a mi modo de ver en forma concluyente, que las normas permisivas producen efectos normativos y por tanto la ausencia de regulación no es pragmáticamente equivalente a la regulación permisiva.

Ad 2) Tengo la impresión de que toda la argumentación de ARM respecto del carácter no independiente de la permisión, basada en que el papel de las normas permisivas puede ser exitosamente cumplido por normas de obligación o de prohibición, se origina en un malentendido. Aparentemente ARM piensan que las normas permisivas sólo pueden ser expresadas en términos de «permitido» y si son formuladas en términos de «prohibido» o de «obligatorio» dejan de ser normas permisivas. Pero esto es un error. Ya LEIBNIZ había observado que los términos «prohibido», «obligatorio» y «permitido» son interdefinibles con la ayuda de la negación y desde VON WRIGHT (1951) ${ }^{16}$ se sabe que las normas pueden expresarse usando cualquiera de esos términos como primitivo y definir los demás a partir él. La interdefinibilidad de los operadores deónticos sólo significa que tanto las normas imperativas, que establecen prohibiciones y obligaciones, como las normas permisivas, que autorizan la realización o la omisión de una acción, pueden ser formuladas en términos de prohibición, obligación o permisión, indistintamente. Pero esto no significa que las normas permisivas sean reemplazables por las normas de prohibición o de obligación o reducibles a ellas. La diferencia entre los dos grandes grupos de normas: normas imperativas (o mandatos en la terminología de ARM) y normas permisivas no depende de los términos que se usen para formularlas y una norma como «Permitido $p »(« \mathrm{P} p »)$ sigue siendo permisiva y no

${ }^{16}$ G. H. von Wright, «Deontic Logic», Mind, núm. 60, 1-15. 
pierde ese carácter, aunque se la formule en términos de prohibición como «No prohibido $p$ » o de obligación «No obligatorio no p», de la misma manera como la norma «No permitido $p »$ es imperativa y no permisiva, aunque en ella no figure el término «prohibido».

Por ejemplo, las expresiones «Permito que se cierre la ventana si llueve» o «No prohíbo que se cierre la ventana si llueve» o «No obligo (no ordeno) no cerrar (omitir cerrar) la ventana si llueve» ${ }^{17}$ son formulaciones distintas de la misma norma permisiva. Ninguna de esas formulaciones expresa un imperativo (o mandato): son claramente normas permisivas, aun cuando en ellas no figura el término «permitido». En general, todo sistema de lógica deóntica que admite la negación delante del operador deóntico $\mathrm{O}$ reconoce la existencia de normas permisivas ${ }^{18}$. De modo que la traducción de las normas permisivas en normas en las que no figura el término «permitido» no prueba en absoluto que el carácter permitido no sea independiente respecto de la prohibición u obligación, ni que las normas permisivas sean teóricamente superfluas.

El error de considerar que las normas formuladas en términos de prohibición (u obligación, que es lo mismo) no pueden ser permisivas se pone de manifiesto en el siguiente párrafo (referido a ALCHOURRÓn y BULYGIN):

«Que una determinada conducta pueda estar simultáneamente permitida en el sentido fuerte y prohibida por parte de dos normas distintas del mismo sistema equivale a decir que los sistemas normativos pueden contener antinomias, lo cual es, a nuestro juicio, indiscutible. Pero esto, por sí solo, no es argumento suficiente para considerar lo que ellos llaman permiso prescriptivo como un carácter independiente de las normas, pues esa situación también se podría describir — sin necesidad de hacer referencia a permisos- como una antinomia entre dos normas, una de las cuales prohíbe una determinada conducta en un determinado caso, mientras que la otra niega esta probibición (esto es, tendría la formulación "no probibido p en el caso q")» (101-102). El subrayado es mío.

Y unas líneas más abajo ARM niegan que la introducción de una norma permisiva sea algo distinto de la negación o cancelación de prohibiciones. A esta altura de las cosas ya debería estar claro que una norma que no prohíbe $p$ en el caso $q$ no es un mandato, ni una prohibición. Una norma que niega o cancela una prohibición es precisamente una norma permisiva (cualesquiera que sean los términos en que se la formule).

En términos generales, las fórmulas expresivas de normas (y no de meras proposiciones normativas) de la forma « Op» y « O O p» son normas permisivas equivalentes a «P p $>$ y $« p p »$, así como la negación delante del operador $\mathrm{P}$ convierte a la norma permisiva en una prohibición.

Ad 3) La tesis de que todas las conductas no prohibidas por el Derecho son ipso facto reguladas por el Derecho como permitidas (ARM, 106) es más que dudosa. De «To-

${ }^{17}$ Uso en estos ejemplos el imperativo en primera persona para subrayar que se trata de normas y no de proposiciones normativas. Como se sabe, las expresiones «es obligatorio», «está prohibido» o «está permitido» son ambiguas y tienen un significado diferente según si figuran en normas o en proposiciones normativas. Por supuesto en algunos casos la formulación usada en estos ejemplos resulta un tanto alambicada, pero el uso del imperativo en primera persona elimina esa ambigüedad.

${ }^{18}$ Si no recuerdo mal, esto se lo señalé a ATIENZA y a Ruiz MANERO en una discusión verbal en su famoso seminario de Alicante en 2002. 
das las conductas están prohibidas o no prohibidas» no cabe inferir que todas las conductas están reguladas por el Derecho. En esta frase «no prohibido» puede referirse a las conductas reguladas como no prohibidas o a todas las conductas que no estén prohibidas. En el primer caso puede tratarse de conductas obligatorias o permitidas; en el segundo caso, puede tratarse de conductas no reguladas en absoluto. En ninguno de los casos se puede inferir que todas las conductas no prohibidas están reguladas como permitidas.

El siguiente ejemplo puede servir para aclarar la situación: De la verdad de «Todas las cosas son azules o no son azules», no cabe inferir que todas las cosas tienen color. Decir que todas las cosas que no son azules tienen color nos llevaría a afirmar que los pensamientos, las leyes y las fórmulas matemáticas tienen color, ya que ciertamente no son azules. El término «no-azul» puede referirse aquí a las cosas que tienen color, pero no son azules. Esto es lo que los escolásticos llamaban términos privativos y los distinguían de los términos indefinidos. Pero si nos referimos irrestrictamente a todas las cosas, el término «no-azul» es indefinido (se refiere a todas las cosas que no son azules) y con este significado «no-azul» no se refiere a una propiedad cromática, y por consiguiente «no-azul» no es un color.

Lo mismo sucede con «no prohibido»: si nos referimos a las conductas reguladas, «no prohibido» es una propiedad, la propiedad de estar regulado y no prohibido (es decir, permitido en el sentido positivo o fuerte), pero aplicado a todas las conductas (aun a las que no están reguladas) el término es indefinido. Así como «no-azul» no es un color, «no-prohibido» no es una regulación normativa.

Se trata aquí de un problema de larga data: el problema de los términos negativos. Los escolásticos distinguían entre dos tipos de términos negativos: los privativos y los indefinidos. Los términos indefinidos eran considerados como meras ficciones, ya que en ellos no hay una genuina atribución de una propiedad a un sujeto y para ellos no vale la ley de Tercero Excluido. El mismo ARISTÓTELES dice (en De Interpretatione, II, $\left.16^{a}, 30\right)$ que la expresión «no-hombre» no es un nombre y agrega que se la podría llamar nombre indefinido.

Como señala ALCHOURRÓN ${ }^{19}$, el mismo problema se ha planteado en la moderna teoría de los conjuntos con la clase de todos los objetos que no pertenecen a una clase dada, clase cuya existencia es rechazada por la mayoría de las teorías de conjuntos, debido a las conocidas paradojas que fueron descubiertas al principio del siglo pasado.

Si el término «no-prohibido» se refiere a la clase de todas las conductas que no están prohibidas (estén o no reguladas) obtenemos una clase a la que pertenece todo lo que no pertenece a una clase dada, cuya existencia difícilmente sea aceptable.

Si aceptamos — como es razonable— que el universo de conductas posibles puede dividirse en dos grandes grupos: conductas reguladas por el Derecho y conductas no reguladas, entonces la dicotomía «prohibido-no prohibido» (todas las conductas están prohibidas o no prohibidas) vale para las conductas reguladas, pero no para todas las conductas irrestrictamente, y de la mera ausencia de prohibición no cabe inferir que la conducta esté regulada como permitida.

19 C. E. AlCHOURRón, «Negación y tercero excluido», Revista Latinoamericana de Filosofía», vol. VII, núm. 1, marzo de 1981, reproducido en Alchourrón-Bulygin, Análisis lógico y Derecho, Madrid, Centro de Estudios Constitucionales, 1991, 561-565. 
3.

La misma idea de la equivalencia pragmática entre la ausencia de regulación y la regulación permisiva aparece en forma aún más acentuada en RUIZ MANERO (2005) ${ }^{20}$ :

«Las acciones no reguladas son precisamente eso, acciones no reguladas y, por ello, carentes de status normativo. Ahora bien, ¿qué implica decir de una acción que carece de status normativo en relación con un cierto sistema de normas? Quiere decir que esa acción no se ve afectada por ninguna norma de ese sistema. $\mathrm{O}$, dicho de otra forma, que —al igual que ocurre con la permisión expresa— ninguna norma de ese sistema es violada por el sujeto tanto si realiza la acción como si se abstiene de realizarla. En este sentido, la disponibilidad de la acción para el sujeto, en relación con ese sistema de normas, es la misma tanto si la acción no esta regulada por el sistema como si la acción está permitida por el sistema. El sistema no impone restricción alguna sobre la conducta en ninguno de ambos casos» (118).

Los argumentos expuestos anteriormente (Ad1) deberían ser suficientes para refutar esta tesis, pero el mismo RUIZ MANERO — y esto es lo curioso del caso- - se encarga en suministrar varios ejemplos de normas permisivas que sí son relevantes, pues producen importantes efectos normativos. Dice RuIz MANERO que una norma permisiva puede cancelar una prohibición, exceptuar una prohibición, aclarar que un cierto caso no está comprendido en el alcance de una prohibición o introducir indirectamente una prohibición (19). Esto es claramente incompatible con la afirmación de que las normas permisivas son irrelevantes.

Su conclusión es:

«... la relevancia de las reglas permisivas parece poder explicarse enteramente en términos de reglas prohibitivas, de derogación o de excepción de las mismas y de definiciones. Así pues, por este lado, no parece haber dificultad para la tesis de que la ausencia de regulación (de prohibición) y la permisión son situaciones equivalentes para el sujeto» (19).

A esto cabe observar, primero, que — como ya se ha argumentado- tales normas son permisivas aun cuando estén formuladas en términos de prohibición, cancelación o derogación y segundo, una cosa es que en ciertas situaciones la ausencia de regulación y la permisión sean equivalentes para el sujeto y otra muy distinta que haya una equivalencia pragmática en todas las situaciones y que las normas permisivas sean normativamente irrelevantes o superfluas en el sentido de que son reducibles a normas imperativas.

RuIZ MANERO, además de radicalizar las tesis expuestas en Las piezas del Derecho, insiste en sostener que las normas imperativas son capaces de realizar todas las funciones de las normas permisivas, por lo cual la sustitución de las normas permisivas por normas imperativas (normas que establecen prohibiciones u obligaciones) puede llevarse a cabo en todos los contextos sin pérdida de significado.

Dejando de lado la cuestión de que todas las normas mediante las cuales RUIZ MANERO pretende sustituir las normas permisivas no son - pese a las apariencias-

${ }^{20}$ J. Ruiz MANERO, «Algunas concepciones del Derecho y sus lagunas», en el libro citado en la nota 14, 103-126. 
imperativas, sino permisivas con ropaje imperativo, es bastante fácil probar que hay funciones que sólo pueden ser desempeñadas por normas permisivas. En NS hay un claro contraejemplo de esa tesis: las normas de clausura tienen que ser permisivas, si se quiere preservar la consistencia del sistema. Pues si la norma de clausura prescribiera que todas las conductas no normadas deben ser consideradas prohibidas u obligatorias, surgirían contradicciones en los casos en que la omisión o la comisión de una conducta no estén normadas. Agradezco a P. NAVARRO, quien en un artículo reciente (todavía inédito) ha llamado mi atención sobre este caso, que prueba en forma concluyente que el papel que cumplen las normas permisivas en ciertos contextos no puede ser cumplido por normas imperativas.

Hay otra línea de pensamiento en RUIZ MANERO que creo no hace al problema de la equivalencia pragmática. Ésta es la idea proveniente de SCHAUER ${ }^{21}$ (y en la que - como veremos luego- insiste mucho BAYÓN) de que el Derecho está constituido por dos niveles normativos: reglas y sus principios subyacentes. Analizaré la incidencia de esta idea en el próximo párrafo.

\section{4.}

El trabajo de BAYÓN de 2009 se centra en dos temas: la naturaleza del principio «todo lo que no está prohibido, está permitido» y la discrecionalidad judicial. Ambos temas están íntimamente relacionados, y la idea de BAYÓN es que esta relación consiste en que los dos están basados en la tesis de la equivalencia pragmática entre la ausencia de regulación y la regulación permisiva.

Respecto del primer tema BAYÓN rechaza el dilema entre trivialidad y contingencia del principio de prohibición y sostiene que hay una tercera posibilidad, a saber, que el principio sea verdadero y no trivial. Su verdad no sería analítica: «permitido» no quiere decir simplemente no prohibido, pues en tal caso el principio sería trivial; tampoco sería una verdad empírica, en cuyo caso sería contingente. Pero BAYÓN es muy categórico en afirmar que «el principio de prohibición podría ser interpretado en un sentido que expresaría una verdad no contingente y no trivial» ${ }^{22}$. Es decir, se trataría de una verdad necesaria (no contingente), pero no analítica (no trivial). Esto sugiere la idea de juicios sintéticos a priori kantianos. La posibilidad de juicios sintéticos y necesarios es discutible, pero como BAYÓN, a diferencia de KANT, no dice nada para justificarlos, prefiero no insistir en este punto.

En su trabajo, BAYÓN se declara ferviente partidario de la tesis de la equivalencia pragmática que es la base para rechazar tanto el «trilema de BuLYGIN» (35), como la discrecionalidad judicial. BAYÓN me atribuye dos equívocos que impedirían ver que el principio de prohibición es una verdad necesaria y no trivial: la falta de distinción entre calificaciones normativas explícitas y calificaciones normativas finales o concluyentes por un lado y la no distinción entre «permisos protegidos» y «permisos no protegidos», por el otro (35).

${ }^{21}$ F. SCHAuER, Playing by the Rules, A Philosophical Examination of Rule-based Decision Making in Law and in Life, Oxford, Clarendon Press, 1991.

22 BAYÓN, 2009: 35. 
5.

Respecto del primer punto referente al doble carácter del Derecho, constituido por reglas o normas explícitamente formuladas y los principios que constituyen las justificaciones subyacentes a las formulaciones normativas explícitas, cabe hacer varias observaciones.

En primer lugar, se trata de un problema que concierne a la identificación de las normas jurídicas a partir de ciertas formulaciones normativas, es decir, de la interpretación de textos jurídicos. Esto no tiene nada que ver con la tesis de la equivalencia pragmática entre la no prohibición y la permisión, ni con el principio de prohibición.

BAYÓN reconoce que se trata de la identificación de las normas jurídicas, entendidas como significados de ciertas expresiones lingüísticas. Coincido con él cuando dice que «la identificación del Derecho puede ser vista como un proceso de explicitación - no de creación o pura invención - de normas» y que los principios subyacentes pueden «suponer en algunos casos la ampliación o la restricción» del tenor literal de las normas expresas, y que «pueden aclarar y zanjar problemas de indeterminación de los que adoleciese su formulación». (Los subrayados son míos.) Pero no creo que puedan «incluso regular casos no contemplados expresamente por ninguna de dichas prescripciones» ${ }^{23}$. Esto último supone ya no una mera explicitación, sino la creación de nuevas normas.

Ahora bien, tal como fueron definidos en NS los conceptos de sistema normativo, laguna normativa, completitud, contradicción normativa, etc. son conceptos relativos, esto es, se trata de relaciones entre un conjunto de situaciones fácticas (casos), un conjunto de calificaciones deónticas de ciertas conductas (soluciones) y un conjunto de normas, es decir, de formulaciones normativas interpretadas. Lo cual implica que el proceso de la determinación o identificación de esas normas ya se ha cumplido; antes de haber identificado esas normas no tiene sentido hablar de lagunas o contradicciones normativas. Por consiguiente, el tema del doble carácter del Derecho y de los principios subyacentes está fuera del ámbito de nuestro tema, salvo que uno crea que el balance entre los principios conduce necesariamente a un conjunto de normas que solucionen todos los casos posibles, es decir, a sistemas cerrados. Es cierto que algunos autores parecen pensar esto; así por ejemplo J. AgUiLó afirma:

«En el nuevo paradigma [postpositivista] no hay casos relevantes no regulados, pues en los sistemas jurídicos no sólo hay reglas, sino también principios» ${ }^{24}$.

Pero esto no es más que una ilusión. En realidad nada garantiza — como lo subraya el mismo BAYÓN- que el balance de reglas y principios conduzca necesariamente a un resultado unívoco, es decir, a la completitud de todos los sistemas posibles.

Con esto no pretendo negar la existencia de los principios o razones justificativas subyacentes a las formulaciones normativas del legislador (aunque tengo la impresión de que su importancia ha sido fuertemente exagerada por autores como DwORKIN

23 BAYÓN, 2009: 49-50.

${ }^{24}$ J. Aguiló, «Positivismo y postpositivismo. Dos paradigmas jurídicos en pocas palabras», Doxa, núm. 30, 2007: 665-675, 673. 
o AleXY), pero considero que su existencia no incide en absoluto en el tema de la equivalencia pragmática. Lo único que hace la introducción de principios es ampliar la cantidad de normas: partiendo de un conjunto (normas formuladas expresamente) llegamos a otro conjunto más amplio formado por las calificaciones definitivas resultantes del famoso balance, pero nada permite pensar que el nuevo conjunto será necesariamente completo.

En este contexto conviene recordar lo que SCHAUER dice acerca del papel de los principios subyacentes y su incidencia en la toma de decisiones basada en reglas ${ }^{25}$. Para SCHAUER, una regla no puede emplearse como fundamento de una decisión si no se la trata como relativamente «opaca» respecto de su justificación subyacente, esto es, si no se la considera «atrincherada» o consolidada respecto de las razones que pudieran justificar su formulación. La formulación verbal de cualquier regla general tendrá casos de subinclusión y también de sobreinclusión respecto de su justificación subyacente, frente a los cuales, si se opta siempre por la solución que resulta de las razones que justifican la regla y no por la que resulta directamente de ella, no se estará fundando la decisión en la regla, sino en tales razones. De esto cabe concluir que, tratándose de normas generales creadas deliberadamente y formuladas en un lenguaje, si no se quiere desconocer el papel que las reglas desempeñan en la toma de decisiones, la autoridad debe ser asignada al texto y no a su autor, a la ley y no al legislador.

En segundo lugar, tenemos que considerar el caso de una laguna normativa que es especialmente interesante en este contexto.

El concepto de laguna normativa, tal como está definido en NS, supone un caso genérico no correlacionado por un determinado conjunto de normas (sistema normativo) con una solución maximal, es decir, no hay ninguna norma (ni formulada, ni derivada) en ese sistema normativo que solucione (en forma completa) este caso. Digo que este caso es especialmente interesante porque es aquí donde el tema del principio de prohibición se vincula con el de la discrecionalidad judicial y con el tema de la simetría o asimetría entre una sentencia que acoge la demanda y la que la rechaza. He sostenido en el seminario de Madrid $^{26}$ la tesis que ya se encuentra en NS: en un proceso civil (en sentido amplio, que sólo excluye los procesos penales) ${ }^{27}$ el juez debe fallar a favor del actor cuando hay una norma jurídica que establece que el demandado debe realizar la conducta exigida por el demandante y debe rechazar la demanda cuando hay una norma que permite al demandado no hacer lo que el actor pretende que haga. Pero en ausencia de toda norma referida a la conducta del demandado (que es el caso de una laguna normativa) el juez no tiene ninguna obligación específica; sólo tiene la obligación de juzgar, es decir, de resolver el pleito, pero lo puede hacer de cualquiera de las dos formas en que se resuelven los procesos normativos: haciendo lugar a la demanda o rechazándola. Se trata, pues, de una situación en la

${ }^{25}$ Cfr. F. SCHAUER, 1991.

${ }^{26}$ Cfr. E. Bulygin, «Creación judicial del Derecho», en el volumen citado en la nota 15.

${ }^{27}$ Siempre que se trate del Derecho penal liberal que contiene una regla de clausura que reputa penalmente lícitas aquellas conductas que no han sido objeto de reproche penal previo. Tal regla es obviamente contingente, pues es el producto de una ideología política, y aunque está bastante difundida en la legislación penal actual, no sólo en el pasado, sino aún hoy, lamentablemente dista mucho de gozar de reconocimiento universal. 
que el juez puede decidir discrecionalmente. Esta tesis implica la simetría entre una sentencia condenatoria y una sentencia denegatoria; en ambos casos la decisión del juez (norma individual) para estar justificada debe estar basada en una norma general que soluciona el caso genérico. Y si no hay tal norma, si estamos en presencia de una laguna normativa, el juez debe invocar alguna otra norma general (que por hipótesis no forma parte del Derecho preexistente) para justificar su decisión, haciendo uso de sus poderes discrecionales.

Frente a esto Bayón sostiene que:

«... aunque el ordenamiento no establezca nada respecto al caso, no se sigue de ello que el juez tenga discreción para decidir en la forma que estime conveniente, sino que tiene el deber de fallar en un sentido perfectamente determinado: en el de desestimar cualquier demanda que pretenda que la realización de la conducta es obligada o está prohibida. La conclusión a la que llega BULYGIN me parece sumamente contraintuitiva. Sostener que cuando alguien pretende hacer valer un derecho que (por hipótesis) no tiene el ordenamiento deja al juez en la posición de decidir discrecionalmente si acoge o no semejante pretensión tiene que ser, en mi opinión, el producto de algún serio malentendido» (39).

Si mi amigo BAYÓN me acusa de incurrir en un serio malentendido, yo podría acusarlo de ignorar cómo los jueces resuelven tales casos. Con bastante frecuencia los jueces civiles prohíben conductas no prohibidas por el Derecho y también ordenan a realizar acciones que no son obligatorias.

Consideremos el siguiente caso real: en el Derecho argentino no existe una norma legislada que prohíba a un abogado a intervenir como letrado patrocinante en un juicio de divorcio entre sus padres. En un caso en que el hijo de la pareja quiso patrocinar a su madre, en un fallo plenario de la Cámara de Apelaciones en lo Civil los jueces lo prohibieron invocando la norma que prohíbe que el hijo sea testigo en un juicio penal contra sus padres. La norma era claramente inaplicable: no se trataba de un juicio penal y el letrado patrocinante no es testigo. La razón subyacente a la prohibición es que los testigos juran decir la verdad (cosa que no ocurre con los abogados) y entonces en el caso de que el padre haya cometido un delito, no se quiere colocar al hijo en el dilema de contribuir a la condena de su padre (si dice la verdad) o a cometer el delito de falso testimonio si miente. Pero ninguna de esas circunstancias concurre en el caso del abogado patrocinante. La norma aplicada «por analogía» claramente no era análoga. No creo que se pueda sostener que los principios subyacentes obligaban a los jueces a dictar la sentencia prohibitiva. Y tampoco se puede afirmar que se trataba de una conducta que el Derecho no regula ni pretende regular. Yo describiría lo que hicieron los jueces como un típico caso de decisión discrecional.

Para reforzar lo dicho, podemos recurrir al muy novedoso ejemplo del poseedor de buena fe que obtuvo un inmueble por título oneroso. Supongamos, además, que el sistema que manejamos no contiene ninguna norma referente al caso (por ejemplo, podría tratarse de los arts. 2777 y 2778 del Código Civil argentino). Si el propietario demanda la devolución del inmueble, basándose en que como legítimo propietario tiene derecho a reivindicar el bien y el demandado alega que puede no devolverlo por ser poseedor de buena fe por título oneroso, no veo por qué el juez tenga que rechazar necesariamente la demanda. F. ATRIA (un precursor y cercano aliado de RUIZ MANERO y de BAYÓN) dice que el demandado no violó ninguna norma y, por tanto, no corres- 
ponde modificar la posición jurídica. Pero ¿cuál es la posición jurídica que el juez tiene que preservar, la del poseedor o la del propietario? Si el juez hace lugar a la demanda, obliga al poseedor a devolver el inmueble sin que haya ninguna norma que lo respalde, y si la rechaza limita el derecho a la propiedad y otorga al poseedor un derecho (el derecho a retener el bien) que antes no tenía. En ambos casos su decisión culmina en una norma. $Y$ en ninguno de los dos casos hay una norma preexistente que resuelva el problema. No se ve ninguna razón ni implícita ni subyacente que obligue al juez a tomar una de las dos decisiones disponibles. En consecuencia, su decisión es discrecional en el sentido de que ninguna de las dos está fundada en el derecho preexistente.

\section{6.}

Aquí llegamos al segundo equívoco que me atribuye BAYÓN. Éste consistiría en negar que la ausencia de regulación (entendida incluso como concluyente) equivalga a la regulación permisiva (67) y esto resultaría, según BAYÓN, de la falta de distinción entre permisos protegidos y no protegidos. Ahora bien, él admite que si se tratara de un permiso protegido, entonces la objeción sería «certera» (68), pero insiste que no lo es porque se trata de un permiso no protegido. Un permiso protegido se diferencia del permiso no protegido en que el primero consiste en que está prohibido a los demás interferir con la conducta permitida, mientras que tal prohibición no se da en el caso del segundo. BAYÓN admite (69) que no existe la alegada equivalencia pragmática entre la ausencia de prohibición y el permiso protegido, pero cree que hay equivalencia entre la no prohibición y el permiso no protegido. Pero al mismo tiempo afirma que el permiso no protegido «no es sin embargo un permiso vacío o carente de consecuencias: porque tiene al menos la de negar que en una situación semejante el juez tenga discreción para decidir» (72).

Si esto es así tiene que haber alguna norma que obligue al juez a rechazar la demanda dirigida a una conducta no prohibida que constituye un permiso no protegido. Pero una norma de esas características no puede surgir misteriosamente de la simple ausencia de regulación. La existencia de tal norma — como de toda norma- es contingente, y si no la hay, el permiso no protegido no es algo distinto de la mera ausencia de una prohibición y, por tanto, contrariamente a lo sostenido por BAYÓN, vacío y carente de consecuencias normativas.

Más aún, la tesis de BAYÓN conduce a consecuencias altamente paradójicas. En efecto, si hay equivalencia pragmática entre la no prohibición y el permiso no protegido y este último es regulado (pues excluye la discreción del juez), entonces resulta que todo caso que por hipótesis no está regulado (mera no prohibición), está regulado. Y si se toma en serio la afirmación de que el permiso no protegido implica ciertas consecuencias normativas resulta que todo caso para el cual por hipótesis no hay consecuencias normativas en el sistema (caso no prohibido), en realidad tiene consecuencias normativas en el sistema (por ser un caso de permiso no protegido). ${ }^{28}$ Creo que estas consecuencias son inaceptables.

${ }^{28}$ Agradezco a Cristina Redondo el haberme sugerido esta última observación crítica. 
7.

Las conclusiones que cabe sacar de este trabajo son:

1. No existe la pretendida equivalencia pragmática entre la no prohibición y la permisión.

2. Las normas permisivas son normativamente relevantes, pues cumplen múltiples funciones normativas.

3. La tesis de que las normas permisivas son teóricamente superfluas en el sentido de que pueden ser reemplazadas por normas imperativas sin pérdida de sentido es insostenible.

4. En vista de la interdefinibilidad de los operadores deónticos $(\mathrm{O}$ y $\mathrm{P})$ con ayuda de la negación, las normas permisivas pueden ser expresadas en términos de negación de prohibición o de obligación, sin convertirse en normas imperativas, así como las normas imperativas (prohibiciones y mandatos) pueden expresarse en términos de (la negación de la) permisión.

5. La concepción del Derecho que comprende reglas y principios subyacentes es irrelevante para el problema de la equivalencia entre regulación negativa (no prohibición) y permisión y para la caracterización de las lagunas normativas.

6. La interpretación de la conducta no prohibida en términos de permisos no protegidos es incompatible con la tesis de la equivalencia pragmática y no precluye la posibilidad de la discrecionalidad judicial.

7. Los jueces civiles pueden, en uso de sus poderes discrecionales, prohibir conductas no prohibidas por el Derecho y ordenar la realización de conductas no obligatorias y lo hacen con relativa frecuencia.

8. Las decisiones judiciales que hacen lugar a la demanda y las que la rechazan son simétricas en el sentido de que ambas contienen normas individuales y toda norma individual requiere para su justificación normas generales.

9. No se advierte de qué manera se puede eludir el dilema entre la analiticidad (trivialidad) y la contingencia del principio de prohibición, que en ningún caso puede ser necesario (no contingente) y no analítico. 